\title{
Distribution, abundance and mortality of cod and haddock eggs and larvae on Georges Bank in 1995 and 1996
}

\author{
David Mountain*, Peter Berrien, John Sibunka \\ Northeast Fisheries Science Center, National Marine Fisheries Services, National Oceanic and Atmospheric Administration
} (NMFS/NOAA), 166 Water Street, Woods Hole, Massachusetts 02543, USA

\begin{abstract}
The eggs and larvae of developing year-classes for cod Gadus morhua and haddock Melogrammus aeglefinus on Georges Bank were sampled during monthly surveys in the winter and spring of 1995 and 1996. The distribution and abundance of the age groups or cohorts within the egg and larval populations were estimated during each survey. The displacement of the cohorts between surveys was largely consistent with advection by the climatological circulation pattern. Egg mortality rates, calculated from the decrease in seasonal total abundance of early and later stage eggs, were 14 and $12 \% \mathrm{~d}^{-1}$ for cod and 12 and $11 \% \mathrm{~d}^{-1}$ for haddock in 1995 and 1996, respectively. Larval mortality rates, calculated from the decrease in the abundance of larval cohorts between surveys, ranged from 3 to $9 \% \mathrm{~d}^{-1}$ for cod and 7 to $14 \% \mathrm{~d}^{-1}$ for haddock, with no evident difference in the rate between the 2 yr. Variability in the larval mortality rate estimates did not exhibit a temporal pattern, suggesting that mortality was chronic and not dominated by events that caused particularly high or low mortality.
\end{abstract}

KEY WORDS: Cod $\cdot$ Haddock $\cdot$ Larvae $\cdot$ Mortality

Resale or republication not permitted without written consent of the publisher

\section{INTRODUCTION}

The cod Gadus morhua and the haddock Melogrammus aeglefinus stocks on Georges Bank have supported commercial fisheries for over $300 \mathrm{yr}$, and are important members of the bank's ecosystem. In addition to the effects of harvesting, the abundance of these stocks is greatly influenced by variations in recruitment. The ratio of the number of recruits to the spawning stock biomass that produced them can vary by an order of magnitude in both species (O'Brien \& Cadrin 1999, Brown \& Munroe 2000). Much of this recruitment variability is believed to be set during the early life stages, when the eggs and developing larvae are vulnerable to a variety of physical and biological factors that can enhance or inhibit their survival (Serchuk et al. 1994).

Cod and haddock spawning on Georges Bank is concentrated in the late winter and spring on the north- eastern part of the bank (Berrien \& Sibunka 1999). Cod has a more protracted spawning period, with large numbers of eggs being found from December through April and peak values occurring in March. Haddock spawning generally takes place from January through June, but is highly concentrated in the April period. The eggs and larvae of both species are pelagic and are transported southwestward from the spawning area by the clockwise circulation around the bank (Lough 1984). Approximately 2 mo after hatching, the larvae metamorphose to juveniles and become demersal.

Mortality rates during the egg and larval stages of marine fishes have been estimated both through enclosure studies and through observations in the field. Campana et al. (1989) conducted monthly surveys around Browns Bank over 3 yr, and estimated mortalities during the egg stage of about $15 \% \mathrm{~d}^{-1}$ for cod and $10 \%$ for haddock. Similar studies for cod in the North Sea determined a value of $14 \%$ in 1976 (Harding et al. 
1978) and of 14 and $21 \%$ in 1987 and 1988, respectively (Heesen \& Rijnsdorp 1989). Enclosure studies of cod obtained estimates of about $10 \% \mathrm{~d}^{-1}$ for yolk-sac larvae and $8 \%$ for older larvae (Gamble \& Houde 1984). Lough (1984) estimated mortality rates for larval cod and haddock on Georges Bank directly from the decrease in numbers between 2 sampling surveys. A patch of larvae of both species was intensely sampled in April 1981 and then re-sampled approximately $30 \mathrm{~d}$ later in May. The estimated mortality rate from hatching to $6 \mathrm{~mm}$ length was 6 to $8 \% \mathrm{~d}^{-1}$ for both species. On the Faroe Plateau, Saville (1956) made similar mortality estimates for haddock from the decrease in numbers between successive surveys. His values ranged from 4 to $16 \% \mathrm{~d}^{-1}$ during the egg and larval period. Using data from $3 \mathrm{yr}$ of egg surveys and subsequent surveys of juvenile abundance, Sundby et al. (1989) estimated the mortality from egg hatching to the early juvenile period to be 6 to $12 \% \mathrm{~d}^{-1}$ for northeast Arctic cod. Larvae collected on Georges Bank during the National Marine Fisheries Service MARMAP (Marine Resources Monitoring, Assessment and Prediction) program (1977 to 1987) were not individually aged, and direct estimates of mortality rates could not be calculated. However, Morse (1989) combined a length-based mortality rate derived from the MARMAP data with growth rates reported in the literature, and estimated larval mortality rates of about $4 \% \mathrm{~d}^{-1}$ for cod and $7 \%$ $\mathrm{d}^{-1}$ for haddock. Lough et al. (1985) made similar estimates for the mortality of herring Clupea harengus larvae on Georges Bank, obtaining a mean value of $5 \% \mathrm{~d}^{-1}$ with a range of 3 to $7 \% \mathrm{~d}^{-1}$ in different years.

The US GLOBEC Georges Bank program was designed to determine the influence of environmental forcing on the bank's ecosystem, with a particular focus on the growth and survival of the early life stages of the cod and haddock populations (GLOBEC 1992). One component of the field program was a monthly bank-wide survey to sample the plankton, including the cod and haddock eggs and larvae. The growth rates for the cod and haddock larvae during 1995 and 1996 have been analyzed and reported by Green et al. (in press). Using those results, our analysis determines the distribution, abundance and mortality rates of the egg and developing larval stages of the cod and haddock populations during the same 2 years.

\section{MATERIALS AND METHODS}

The GLOBEC program on Georges Bank conducted monthly surveys of the bank from February to July in 1995 and from January to June in 1996. The surveys occupied a set of 38 standard stations in 1995, with a 39th added in 1996 (Fig. 1). In 1995, to better define and sample larval patchiness, a closely spaced grid of stations was occupied at the end of some surveys in an area where high concentrations of larvae had been observed at the standard stations. To increase the number of larval samples collected, this additional sampling effort was replaced in 1996 with a bongo net tow, approximately half way between the standard stations.

Ichthyoplankton samples were collected with both a $61 \mathrm{~cm}$ bongo net and a $1 \mathrm{~m}^{2}$ 'multiple opening and closing net and environmental sensing system' (MOCNESS) (Wiebe et al. 1985). At each standard station, weather permitting, a bongo tow and a MOCNESS tow were conducted to collect fish eggs and larvae. The 2 nets on the bongo frame were each fitted with $333 \mu \mathrm{m}$ mesh nets. A double-oblique tow was made to within $5 \mathrm{~m}$ of the bottom or to a maximum depth of $200 \mathrm{~m}$. The net was towed at a speed of 1.5 to 2 knots, and was adjusted to maintain a wire angle of approximately $45^{\circ}$. A flow meter was mounted in the mouth of the net to measure the volume filtered during the tow. A conductivity/temperature/depth (CTD) instrument was mounted on the wire just above the net frame to provide real-time temperature and salinity data during the tow and to indicate when the tow approached the maximum depth to be sampled. The sample from 1 net was preserved in 5\% formalin; the sample from the second net was preserved in ethanol. The MOCNESS was deployed with 10 nets (0 to 9) to collect both zooplankton and larval fish samples. The system was towed at 1.5 to 2 knots, and was adjusted to keep the frame at an angle of approximately $45^{\circ}$. A flow meter was mounted on the top of the frame to measure the volume filtered during the tow. The system was lowered to the maximum sampling depth with Net 0 open. The frame was then retrieved, sampling depth layers with Nets 1 to 4 (150 $\mu \mathrm{m}$ mesh netting) for zooplankton. At the surface Net 5 was opened and the frame was

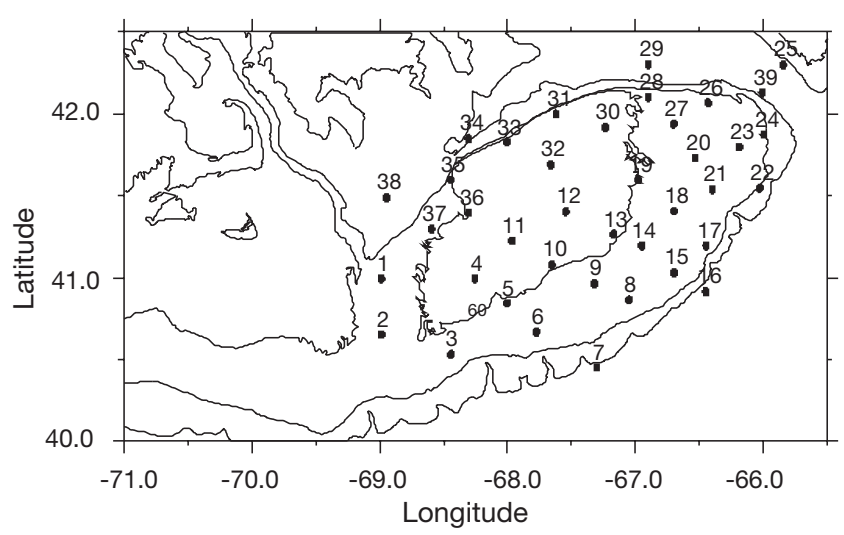

Fig. 1. Standard station locations in Georges Bank GLOBEC Broad Scale Survey 
again lowered to the maximum sampling depth. The frame was then retrieved, with Nets 6 to 9 sampling designated depth layers for larvae (335 $\mu \mathrm{m}$ mesh netting). A standard protocol for depth strata was used: 0 to 15,15 to 45,45 to 100 and 100 to $200 \mathrm{~m}$. The larval samples were preserved in $95 \%$ ethanol. After $24 \mathrm{~h}$, the ethanol in both the bongo and MOCNESS samples was replace with fresh $95 \%$ ethanol.

Fish eggs were sorted from the formalin-preserved bongo samples. Fish larvae were sorted, identified and enumerated by length from all bongo and MOCNESS samples.

The cod and haddock eggs were identified and the following developmental stages enumerated: (1) fertilized to blastopore almost closed; (2) blastopore closed to tail bud almost free (undercut at tip) from yolk surface; (3) tip of tail bud free from yolk surface to tail tip twisting and flexing $<45^{\circ} ;$; $(4)$ tail tip flexed and twisted $45^{\circ}$ to embryo encircles three-quarters of egg circumference; (5) embryo encircling more than threequarters of egg circumference to full circle; (6) embryo encircling $>$ full circle to just before hatching; (7) dead and abnormal stages (not used in any calculations). These stage classifications are essentially the same as those identified by Thompson \& Riley (1981). For a more complete description of gadid egg development see Hardy (1978).

The eggs of the 2 species are indistinguishable at developmental stages prior to tail twisting and flexing, and both can be confused with witch flounder eggs Glyptocephalus cynoglossus until slightly after blastopore closure. The numbers of eggs within these earlier stages for each of the 3 species were estimated by apportioning the total early egg abundance at a station in the same proportions as the older, identifiable egg stages for the 3 species at the same or adjacent stations.

To estimate egg densities and the rates of egg mortality and egg hatching, the egg numbers were grouped into 2 combined stages: from just fertilized to the embryo encircling three-quarters of the egg circumference (Stages 1 to 3), and a second category of more than three-quarters around to hatching (Stages 4 to 6). At a typical incubation temperature of $5^{\circ} \mathrm{C}$, these groupings encompass 59 and $41 \%$ of total development time, respectively. Incubation-rate data for cod are from Thompson \& Riley (1981). Haddock eggs were considered to have the same incubation rates, based on other reports (notably Page \& Frank 1989). The nominal dates for the first and last occurrence of both egg stages in Georges Bank waters were derived from historical egg data in conjunction with the abovenoted incubation rates.

The number of eggs for each stage collected in each bongo tow of a survey was standardized to no. $10 \mathrm{~m}^{-2}$ of sea-surface area, and a mean abundance for the survey was calculated using a delta mean (Pennington \& Berrien 1984). The survey mean abundance for each egg stage was divided by the mean duration of the stage to determine the mean daily egg abundance (no. $10 \mathrm{~m}^{-2} \mathrm{~d}^{-1}$ ) for the survey. The weighted mean date of occurrence for each stage on the survey was also calculated. A daily egg abundance was determined for each day by linearly interpolating between the survey mean abundance values or between zero values on the dates of first and last occurrence and the values for the first and last surveys, respectively. The total egg production (no. $10 \mathrm{~m}^{-2}$ ) for the egg stage was the sum of the daily abundance values over the period from first to last occurrence.

The average egg-mortality rate was calculated by assuming an exponential decline over time between the mean abundance for the 2 egg stages:

$$
N_{t}=N_{0} \cdot \mathrm{e}^{-M t}
$$

where $M=$ mortality rate $\left(\mathrm{d}^{-1}\right), N_{0}=$ mean abundance for the first egg group, $N_{t}=$ mean abundance for the second egg group, and $t=$ time in d between the midpoint of the 2 groups, such that:

$$
M=-t \cdot \ln \left(\mathrm{N}_{t} / \mathrm{N}_{0}\right)
$$

The mortality rate as percent mortality $\mathrm{d}^{-1}(A)$ was calculated by:

$$
A=100 \cdot\left(1-\mathrm{e}^{-M}\right)
$$

This season-long mortality rate was derived for both years from all surveys within each year. It was assumed that any bias caused by estimating mortality during times of increasing or decreasing spawning rates was effectively countered by using data from all portions of the spawning season.

The egg mortality rate was used to project the lateegg-stage abundance at each station forward in time to estimate abundance at hatching (no. $10 \mathrm{~m}^{-2}$ ). These abundances were normalized to daily values by stage duration, and spatially integrated using kriging (see below) over the survey area to estimate a daily mean hatching abundance (no. $10 \mathrm{~m}^{-2} \mathrm{~d}^{-1}$ ) for each survey. A weighted mean hatching date was calculated for each survey. Daily hatching abundance was determined by linear interpolation for each day from the first to last dates of occurrence. The daily values were summed for $10 \mathrm{~d}$ intervals (e.g. Calendar Days 21 to 30) for use in the larval mortality calculations described below.

The age of the ethanol-preserved larvae was determined by counting the daily growth increments on the otoliths (Green et al. 2003). From the ages and measured lengths, Green et al. (2003) derived age-length relationships for the cod and the haddock larvae on each survey for which sufficient otoliths were avail- 
able. For the February to May period, that is the focus of the analyses presented here, age-length relationships are lacking for haddock in February 1995 and May 1996. For those 2 surveys the relationships for March 1995 and April 1996, respectively, were used. From the age-length relationships, the ages of all larvae captured and measured on each survey were estimated from the measured length. Using the age and the date of capture, the hatch date of each larva was determined. The larval populations were separated into cohorts according to hatch date; $10 \mathrm{~d}$ bins were used to define larval cohorts. For example, all cod larvae with hatch dates from Calendar Days 51 to 60 in 1995 were considered as a group and referred to as the $55 \mathrm{~d}$ cohort (for the mid-day of the bin) for cod in that year. The $10 \mathrm{~d}$ bins are the same as those used for the egg-hatching values described above. For each net tow, the abundance of larvae (no. $10 \mathrm{~m}^{-2}$ ) in a cohort was determined from the number of larvae caught in that cohort, the volume filtered by the net, and the depth interval sampled. For MOCNESS tows, the total abundance for each station is the sum of the abundances for the individual nets that made up the vertical profile. From the abundance values at each station, the spatial distribution of abundance for each cohort was determined for each survey on which that cohort was sampled. For stations where larvae were available from more than 1 tow (e.g. a bongo net and a MOCNESS tow), the average abundance was used.

The abundance of a cohort on a survey was determined by interpolating the abundance values (no. $10 \mathrm{~m}^{-2}$ ) for the cohort onto a closely spaced grid of points. The grid used was the Bank-150 grid developed for the GLOBEC finite-element circulation model (Naimie et al. 1994). The grid has 1200 node points and covers the area inside the $150 \mathrm{~m}$ depth contour where broad-scale sampling provides good spatial coverage. To interpolate the observed abundance values to the grid points, the egg and larval abundance values were first log-transformed. Ordinary kriging (Deutsch \& Journel 1998) was then used to determine the value at each grid-point. The resulting grid point values were re-transformed to yield the abundance (no. $10 \mathrm{~m}^{-2}$ ) at each grid point. Multiplying that density by the area represented by the grid point and summing for all grid points provided an estimate of the total number of eggs or larvae for the survey. The area of the bank covered by the grid is $35898 \mathrm{~km}^{2}$. Because of the patchy nature of the egg and larval distributions (e.g. see Figs. 9 \& $10)$, the local mean-abundance value exhibited large spatial variability. To accommodate this, the ordinary kriging calculation was performed with only the 6 observed values nearest the grid point in question. A variogram was determined for the cod and haddock data on each survey using the EasyKrig program of
Chu (1999; available at: ftp://globec.whoi.edu/pub/ software/kriging/easy-krig/V.2.1). An average or characteristic variogram was then determined for each species and used in the kriging calculations.

An abundance estimate was determined for each cohort on each survey during which the cohort was observed. Subjective decisions were made to reject estimates when either the sampling period overlapped the hatch-date window for the cohort, the area of high larval density extended beyond the sampling domain, or there were too few larvae caught to provide a meaningful abundance estimate. The abundance numbers are expressed as the average $10 \mathrm{~m}^{-2}$ of sea-surface area.

Larval mortality rates were estimated in 2 situations. First, when the abundance of a larval cohort was available on 2 successive surveys, the mortality rate was determined from the difference in abundance between the surveys, assuming the exponential form in Eq. (1) where, now, $N_{0}$ is the number of larvae on the first survey, $N_{t}$ is the number of larvae on the second survey, and $t$ is the time in days between surveys. In the second situation, the mortality rate of a cohort was determined between the time of hatching and the first survey for which a larval abundance for the cohort was available. In this situation, $N_{0}$ is the egg hatching abundance for the cohort, as described earlier, $N_{t}$ is the cohort abundance from the first survey from which an abundance estimate was available, and $t$ is the time between hatching and the survey.

To estimate the drift that would be expected for the planktonic eggs and larvae between surveys, bimonthly climatological flow-fields derived by a finiteelement circulation model for the Gulf of Maine/ Georges Bank region (Naimie et al. 1994) were used. Drift tracks were determined from the modeled flow field using the method of B. O. Blanton (unpubl. data).

\section{RESULTS}

The seasonal average egg-mortality rates were 14 and $12 \% \mathrm{~d}^{-1}$ for cod and 12 and $11 \% \mathrm{~d}^{-1}$ for haddock in 1995 and 1996, respectively. These values are comparable to other values in the literature (e.g. Harding et al. 1978, Campana et al. 1989, Heesen \& Rijnsdorp 1989). However, the rates are somewhat higher than those calculated from the MARMAP sampling program, which averaged about $10 \% \mathrm{~d}^{-1}$ for cod and $8 \% \mathrm{~d}^{-1}$ for haddock (P. Berrien unpubl. data). The estimated egghatching rates showed a relatively narrow, peaked distribution in 1995, and a broader distribution in 1996 for both species (Fig. 2). The dip in hatching rate for both species between Calendar Days 65 and 85 in 1996 may have been due to wind-driven, off-bank transport of eggs at the beginning of March. The GLOBEC program 

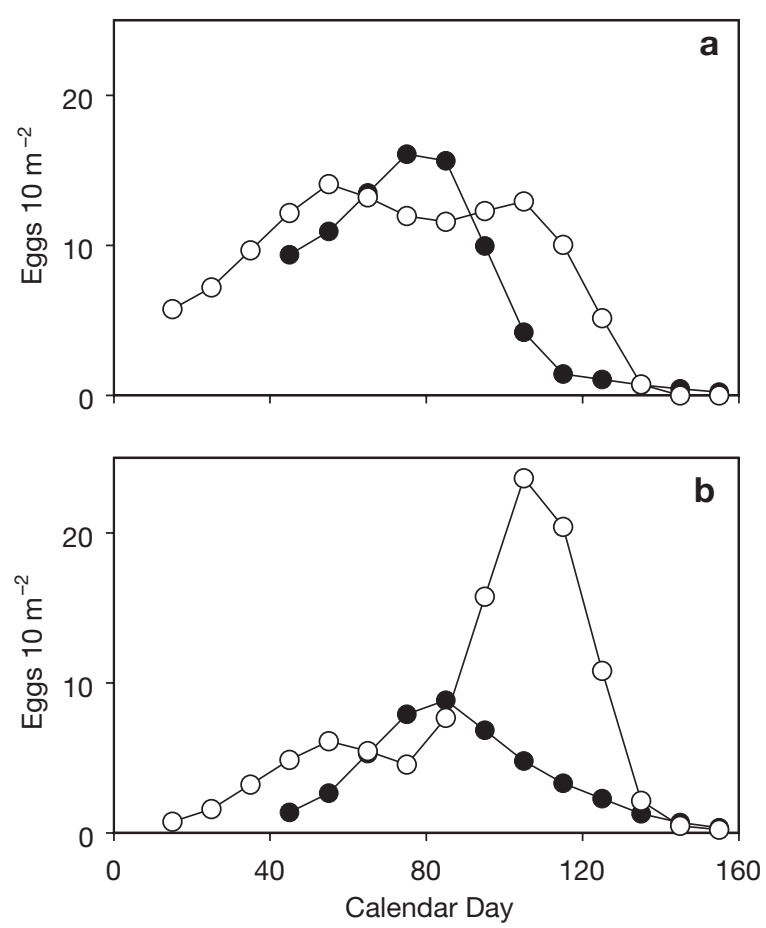

Fig. 2. Gadus morhua and Melanogrammus aeglefinus. Egg-hatching rates for (a) cod and (b) haddock in 1995 and 1996 (O)

had 11 satellite drifters on the bank in late February 1996. From Day 59 to 62 the drifter tracks indicated the characteristic clockwise around-bank flow (Fig. 3). Beginning on Day 63, the buoys abruptly changed direction, moving east or southeast for at least the next $4 \mathrm{~d}$. The 2 buoys on the northeast part of the bank were transported off the bank, past the $200 \mathrm{~m}$ isobath. During the February survey, the eggs for both species were concentrated in this area (e.g. Fig. 9). The estimated total number of eggs hatched for cod was similar in both years, while that for haddock greatly increased from 1995 to 1996. Summing the hatching rates in Fig. 2 from mid-February to the end of June, when comparable data was available in both years, the total hatching for cod was 84 eggs $10 \mathrm{~m}^{-2}$ in 1995 and $104 \times 10 \mathrm{~m}^{-2}$ in 1996. Total hatching for haddock more than doubled, from $46 \times 10 \mathrm{~m}^{-2}$ in 1995 to $102 \times 10 \mathrm{~m}^{-2}$ in 1996 .

The survey sampling-protocol did not synchronize sampling with light conditions or time of day. To insure that no day-night bias occurred in larval catchability, the length-based catch curves (the percent of the total catch that was caught for each millimeter length increment) were determined separately for day samples and for night samples for both cod and haddock (Fig. 4). Daytime was calculated as $2 \mathrm{~h}$ after sunrise to $2 \mathrm{~h}$ before sunset, and night as $2 \mathrm{~h}$ after sunset to $2 \mathrm{~h}$

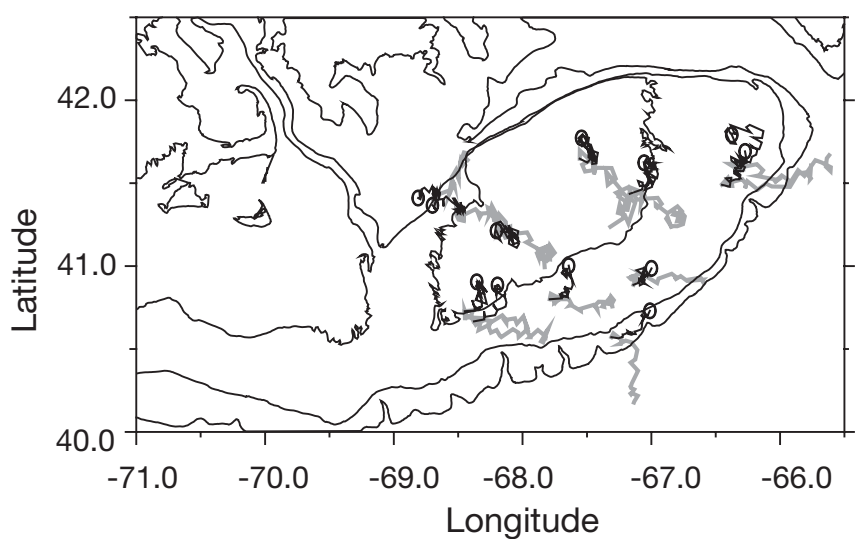

Fig. 3. Movement of satellite-tracked buoy-drifters drogued at $10 \mathrm{~m}$ depth in late February to early March 1996. Black lines: Calendar Days 59 to 62; gray lines: Calendar Days 63 to 66; circles indicate location of drifter on Day 59

before sunrise. For both species, the day and night curves closely overlap and show no indication of a bias toward lower daylight catches due to net avoidance.

The occurrence of larvae as a function of depth and age was determined from the MOCNESS samples for 10-d age bins and for the depth ranges of the MOCNESS sampling ( 0 to 15,15 to $45,>45 \mathrm{~m}$ )

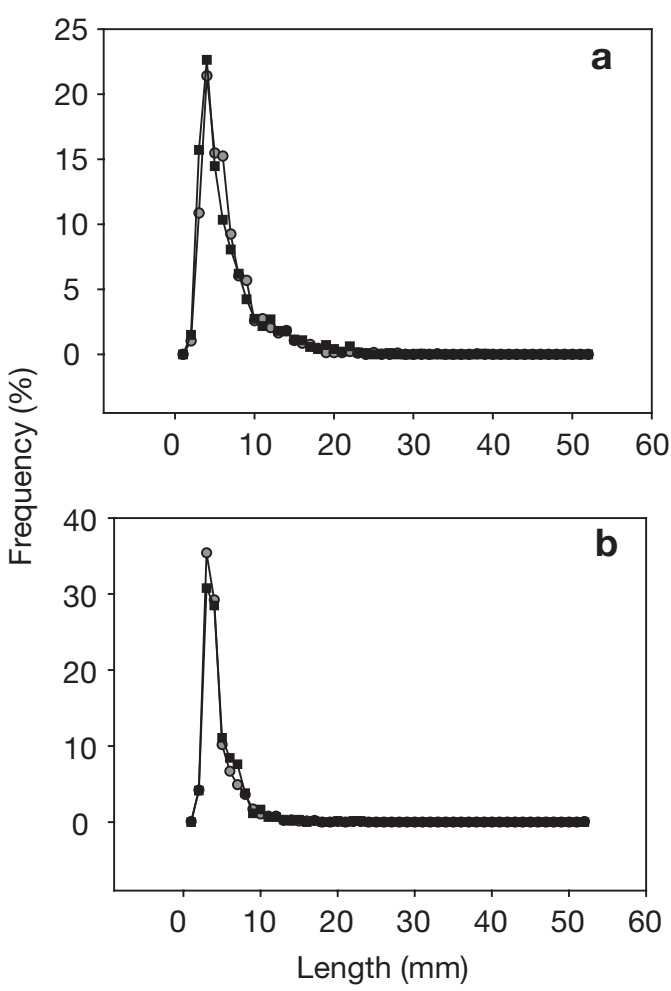

Fig. 4. Gadus morhua and Melanogrammus aeglefinus. Histograms of percent total (a) cod and (b) haddock larvae catch for 1995 and 1996 by $1 \mathrm{~mm}$ length increments. (o) Day time samples; (घ) nighttime samples 
Table 1. Gadus morhua and Melanogrammus aeglefinus. Larval abundance (no. $10 \mathrm{~m}^{-2}$ ) by cohort for cod and haddock in the different surveys (indicated by month) in 1995 and 1996. Calendar Day = cohort hatch date

\begin{tabular}{|c|c|c|c|c|c|c|c|c|c|c|}
\hline \multirow[t]{2}{*}{ Cohort } & \multirow[b]{2}{*}{25} & \multirow[b]{2}{*}{35} & \multirow[b]{2}{*}{45} & \multirow[b]{2}{*}{55} & \multicolumn{2}{|c|}{ Calendar Day } & \multirow[b]{2}{*}{85} & \multirow[b]{2}{*}{95} & \multirow[b]{2}{*}{105} & \multirow[b]{2}{*}{115} \\
\hline & & & & & 65 & 75 & & & & \\
\hline \multicolumn{11}{|c|}{ (a) Cod (1995) } \\
\hline Feb & & 0.84 & & & & & & & & \\
\hline Mar & & 0.63 & 0.96 & 3.63 & 5.36 & & & & & \\
\hline Apr & & & & 0.37 & 0.71 & 2.99 & 4.93 & 2.65 & & \\
\hline May & & & & & 0.18 & 0.52 & 1.10 & 1.26 & 0.49 & 0.24 \\
\hline \multicolumn{11}{|c|}{ (b) Cod (1996) } \\
\hline Feb & 0.52 & 2.27 & & & & & & & & \\
\hline Mar & 0.27 & 0.90 & 1.73 & 4.96 & 3.91 & & & & & \\
\hline Apr & & & 0.41 & 0.79 & & 1.88 & 10.10 & & & \\
\hline May & & & & & & & 0.18 & 0.26 & 2.12 & \\
\hline \multicolumn{11}{|c|}{ (c) Haddock (1995) } \\
\hline Mar & & & & & 2.22 & & & & & \\
\hline Apr & & & & & & 0.56 & 0.53 & 0.85 & & \\
\hline May & & & & & & & & 0.13 & 0.10 & 0.63 \\
\hline \multicolumn{11}{|c|}{ (d) Haddock (1996) } \\
\hline Feb & & 0.36 & 0.72 & & & & & & & \\
\hline Mar & & & 0.18 & 0.50 & 1.21 & & & & & \\
\hline Apr & & & & & & & 1.22 & 4.17 & & \\
\hline May & & & & & & & & & 0.48 & 0.86 \\
\hline
\end{tabular}

(Table 1). The percentage of occurrence was based on the number of larvae caught per cubic meter of water filtered by the nets. For both species, the larvae were concentrated in the middle and upper water column, and the vertical distribution did not change as the larvae aged. These findings are similar to those reported by Lough (1984).

The abundance of each larval cohort on each survey for which an estimate could be made is listed in Table 2 for cod and for haddock. The abundance of the cod cohorts was comparable between the years, although in 1996 the values were somewhat higher than in 1995. The abundance of the haddock cohorts was lower than that for cod, and haddock abundance estimates were possible in much fewer cases. Haddock larval abundance generally greater was in 1996 than in 1995.

The mortality-rate estimates in both years for the cod and haddock cohorts are presented in Figs. 5 \& 6, respectively. The values for cod were generally between 3 and $8 \% \mathrm{~d}^{-1}$. The mortality values were fairly

Table 2. Gadus morhua and Melanogrammus aeglefinus. Percent larvae caught in 3 depth ranges by $10 \mathrm{~d}$ age-bins for cod and haddock from MOCNESS samples in 1995 and 1996

\begin{tabular}{|c|c|c|c|c|c|c|c|c|c|c|}
\hline \multirow{2}{*}{ Depth (m) } & \multicolumn{5}{|c|}{ Cod age (d) } & \multicolumn{5}{|c|}{ Haddock age (d) } \\
\hline & 5 & 15 & 25 & 35 & 45 & 5 & 15 & 25 & 35 & 45 \\
\hline $0-15$ & 41 & 46 & 42 & 48 & 46 & 44 & 49 & 43 & 49 & 43 \\
\hline $15-45$ & 29 & 32 & 32 & 32 & 28 & 29 & 30 & 27 & 40 & 30 \\
\hline$>45$ & 30 & 22 & 26 & 20 & 26 & 27 & 21 & 30 & 11 & 27 \\
\hline
\end{tabular}

evenly distributed across cohorts and throughout the season in both years, such that there was no temporal pattern to the mortality rates. The cod mortality rate appears to have decreased slightly with increasing larval age (Fig. 7), although the slope of the regression line is not significantly different from zero. For haddock the mortality rates were higher than for cod, generally 7 to $14 \% \mathrm{~d}^{-1}$. Haddock mortality rates exhibited a significant decrease with increasing larval age (Fig. 8), with the slope of the regression line significantly different from zero $(p<0.05)$. These rates were derived primarily from the decrease in abundance between egg hatching and the first survey on which the cohort was sufficiently sampled as larvae. The range of larval ages represented in the haddock estimates is considerably smaller than in the cod estimates.

To illustrate the spatial distributions of larval cohorts and the changes in these distributions between surveys, the 55 and $65 \mathrm{~d}$ cod cohorts in March and April of both years have been considered. Both cohorts originated from eggs sampled on the February surveys. The egg distributions during February in both years were fairly similar (Fig. 9). The early-stage eggs were concentrated on the northeast part of the bank, while the late-stage eggs were located somewhat further to the southwest. For the observed water temperatures, the early-stage eggs would have been about $3 \mathrm{~d}$ old and would have hatched in another $16 \mathrm{~d}$, with hatching centered around Calendar Day 62 in 1995 and Calendar Day 68 in 1996. To the extent that the direct observations provide, these early-stage eggs represent the 


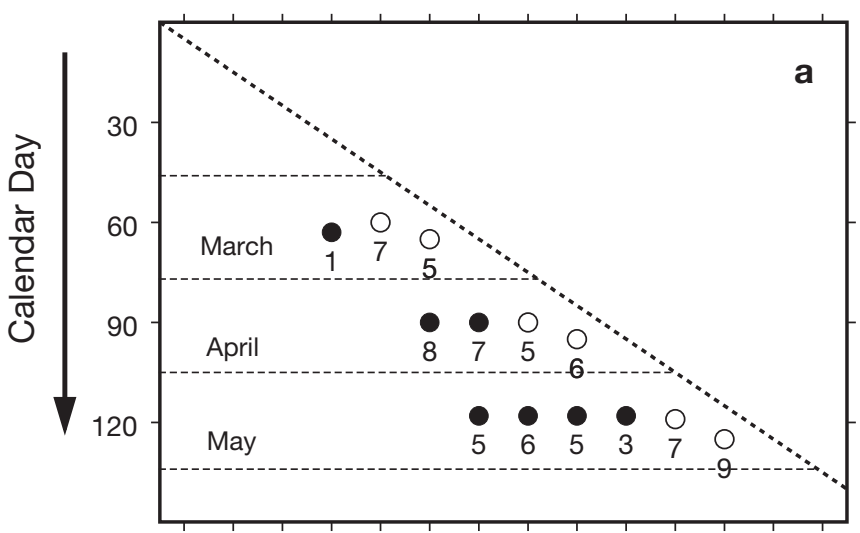

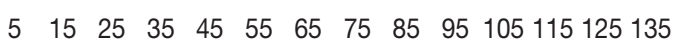

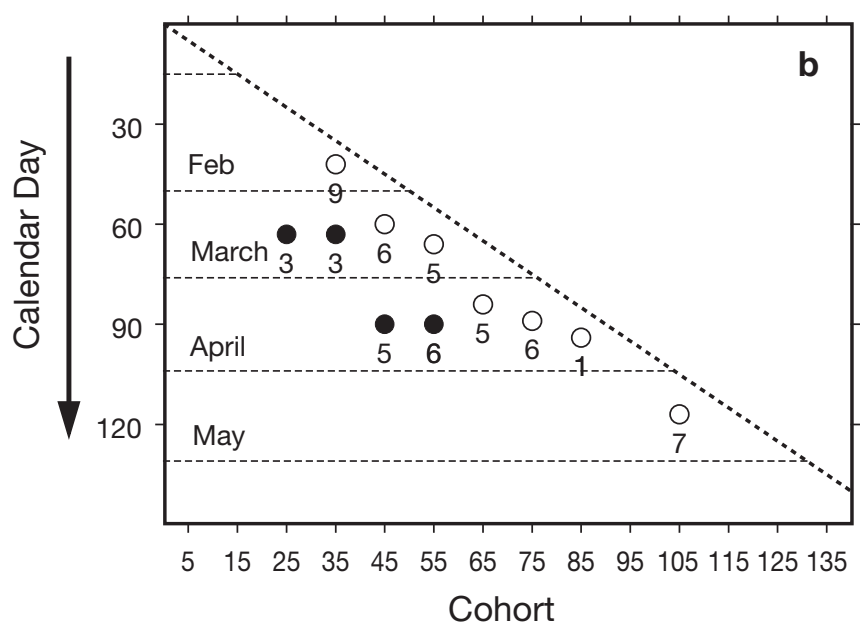

Fig. 5. Gadus morhua. Mortality $\left(\% \mathrm{~d}^{-1}\right)$ for cod larvae in (a) 1995 and (b) 1996; numbers below circles = estimated mortality rates. Positions of circles indicate to which cohort (Cohorts 5 to 135 on horizontal axis) and when during the year (Calendar Days on vertical axis) mortality rates apply. Horizontal dashed lines: times of monthly surveys; (0) mortality rates estimated from decrease in larval abundance estimates between successive surveys (plotted at midpoint of time between the respective surveys); (O) represent mortality rates determined from decrease in abundance from egg-hatching (Fig. 2) to first estimate for cohort abundance as larvae on a subsequent survey (plotted halfway between time of hatching and time of survey)

origin of the $65 \mathrm{~d}$ cohort in both years. The late-stage eggs were about $15 \mathrm{~d}$ old and would have hatched in another 4 d, centered around Calendar Day 50 in 1995 and Day 54 in 1996. These eggs represent the origin of the $55 \mathrm{~d}$ cohort.

Both cohorts were first sampled as larvae in the March surveys. In March 1995, the $65 \mathrm{~d}$ cohort (Fig. 10a) was concentrated in a large patch on the northeast part of the bank. The location was essentially the same as for the early-stage eggs in February, suggesting that little advection had occurred in this area between the February and March surveys. In April, the patch (Fig. 10b) was displaced about $60 \mathrm{~km}$ to the southwest of its March location. The peak abundance was greatly reduced in April, reflecting the mortality that occurred in the month between the surveys. The $55 \mathrm{~d}$ cohort distribution exhibited 2 high-density concentrations in both March and April 1995 (Fig. 11a,b), with the peak densities again greatly reduced in April; 1 patch in April was located on the northern flank of the bank and its association with either of the March patches is not immediately evident. However, the displacement of the centers of distributions for both cohorts from March to April was consistent with a $30 \mathrm{~d}$, mid-depth drift according to the GLOBEC climatological flow field for the March/April period (Figs. 12 \& 13). The flow pattern supports the conclusions that the origin of the patch on the northern side of the bank in April was the western concentration observed in March and, more generally, that cod larvae were transported from the southern to the northern side of the bank.

In 1996, the distributions of the $55 \mathrm{~d}$ (Fig. 11c,d) and $65 \mathrm{~d} \operatorname{cod}$ cohorts (Fig. 10c,d) show the cod larvae to have been further southwest, or more clockwise
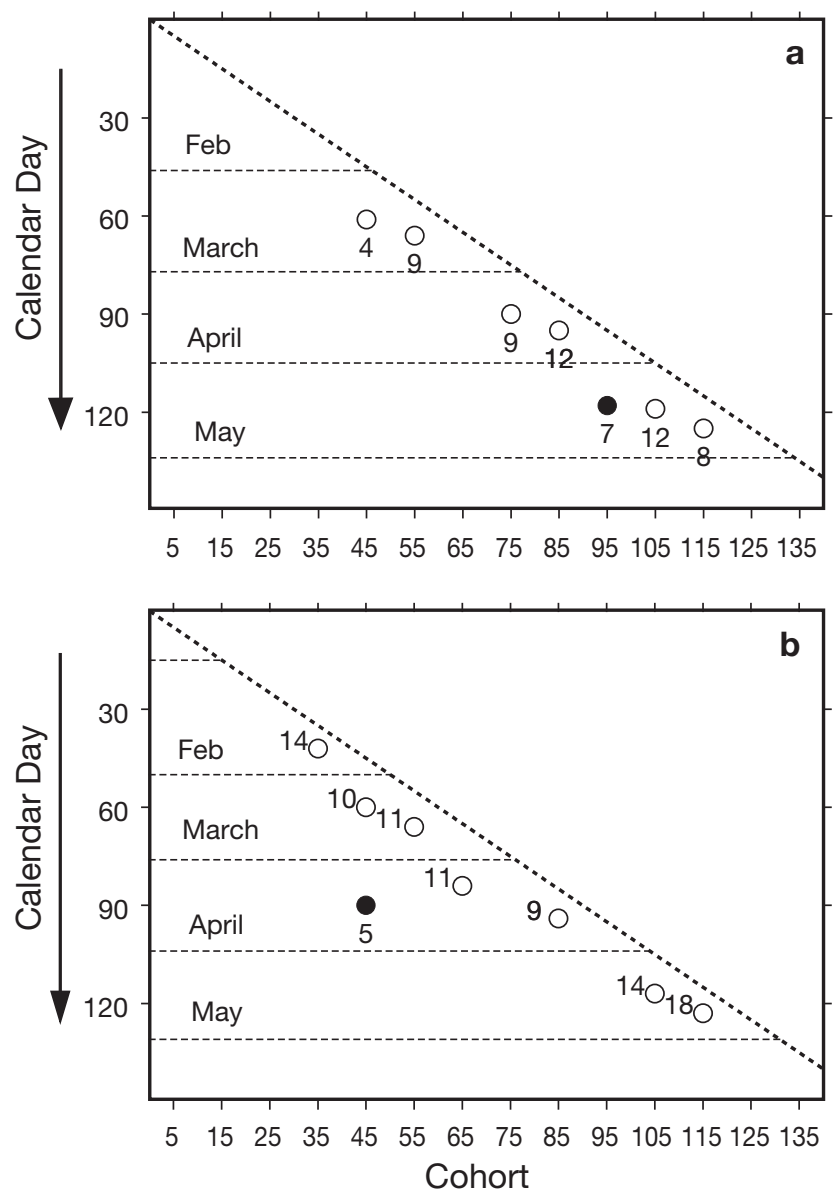

Fig. 6. Melanogrammus aeglefinus. Mortality $\left(\% \mathrm{~d}^{-1}\right)$ for haddock larvae in (a) 1995 and (b) 1996. Details as in Fig. 5 


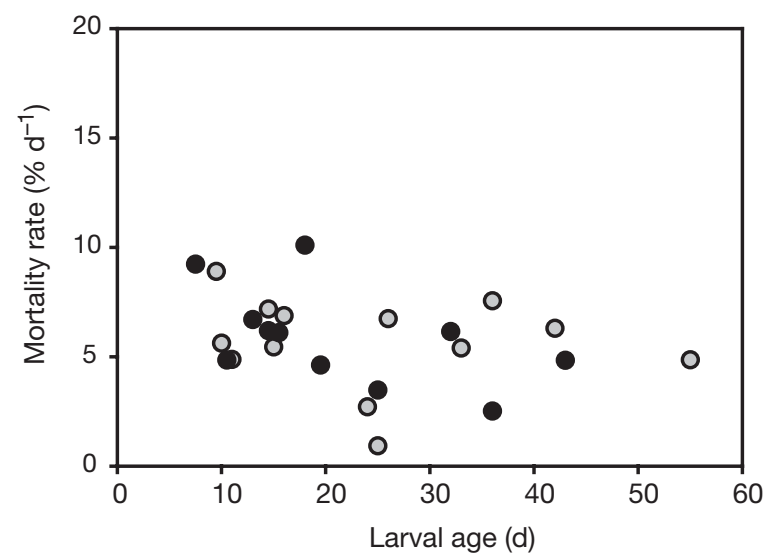

Fig. 7. Gadus morhua. Mortality rate as a function of larval age

around the bank, than at the same time in 1995 (Figs. 11a,b \& 10a,b). Also, in 1996 the cohort concentrations were located further southward toward the southern edge of the bank relative to the corresponding distributions in 1995. This cross-isobath difference may have been caused by the wind event in early March 1996, reflected in the buoy tracks in Fig. 3. As in 1995, the around-bank displacement of the patch centers from March to April in 1996 was consistent with

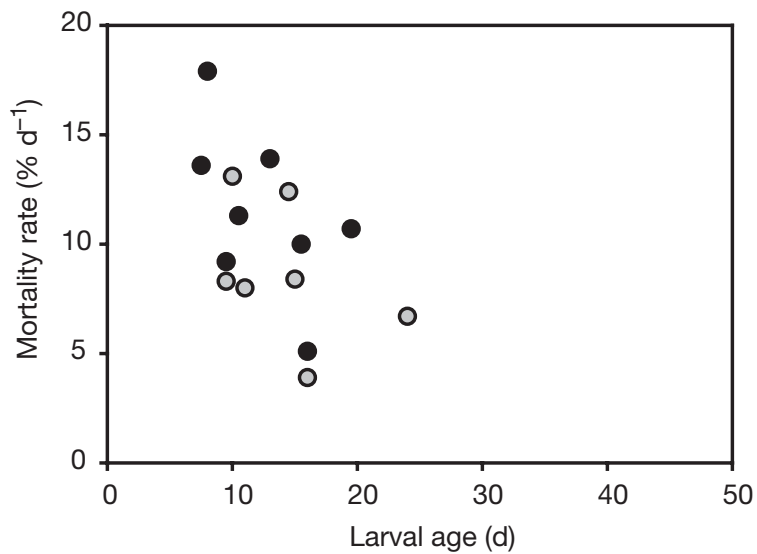

Fig. 8. Melanogrammus aeglefinus. Mortality rate as a function of larval age

the mid-depth climatological flow field (trajectories not shown). In April 1996, the high-density concentration for the $65 \mathrm{~d}$ cohort (Fig. 10d) appears to have extended southwest out of the sampling area toward the Middle Atlantic Bight. As a result, an estimate of the cohort abundance was not included in Table 2, since it would probably significantly underestimate the actual abundance of the cohort. The $55 \mathrm{~d}$ cohort in April 1996 was centered in Great South Channel (Fig. 11d), although a

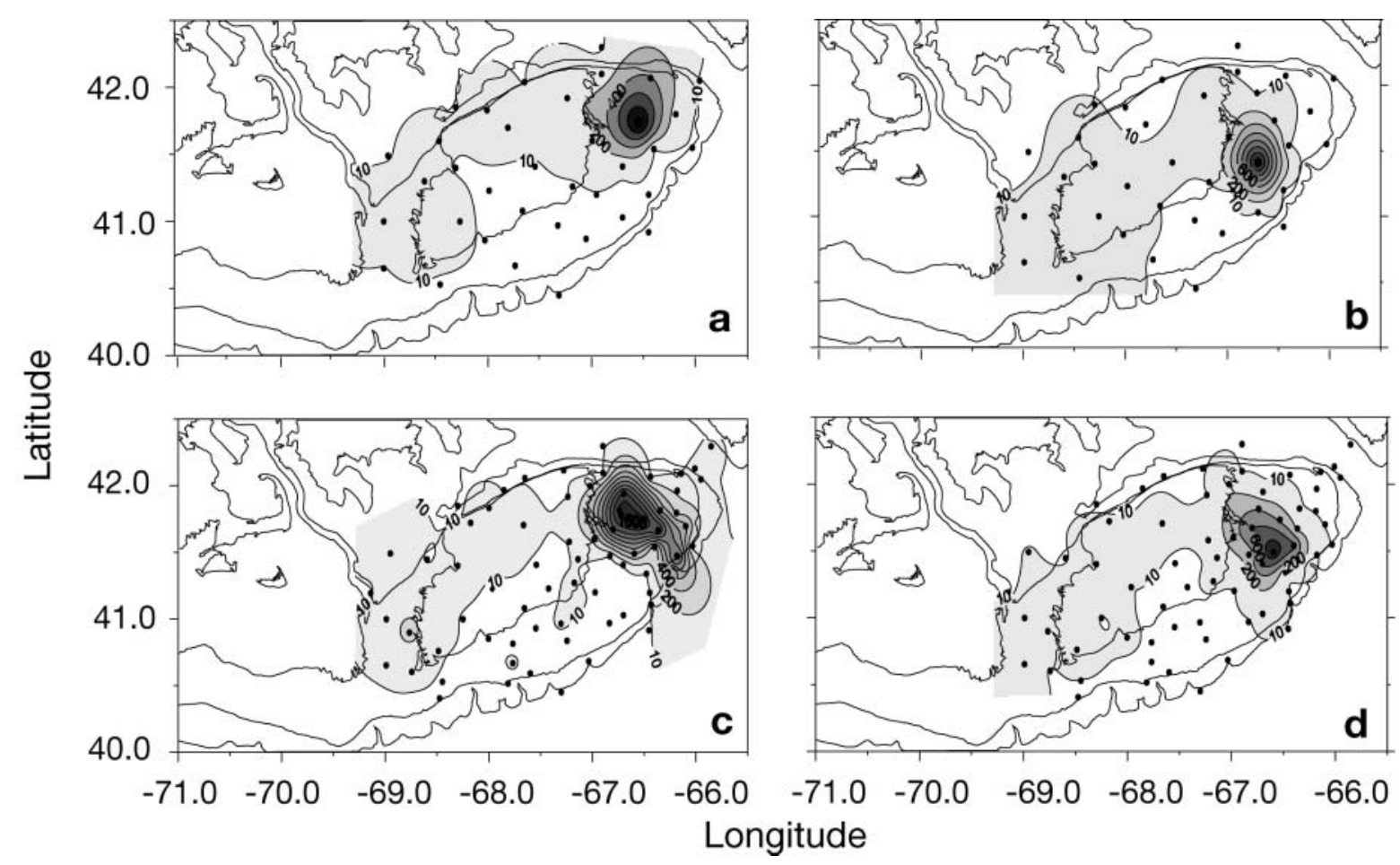

Fig. 9. Gadus morhua. Distribution of (a) early- and (b) late-stage eggs in February 1995, and of (c) early- and (d) late-stage eggs in February $1996\left(\right.$ no. $10 \mathrm{~m}^{-2}$ ). Station positions as in Fig. 1 


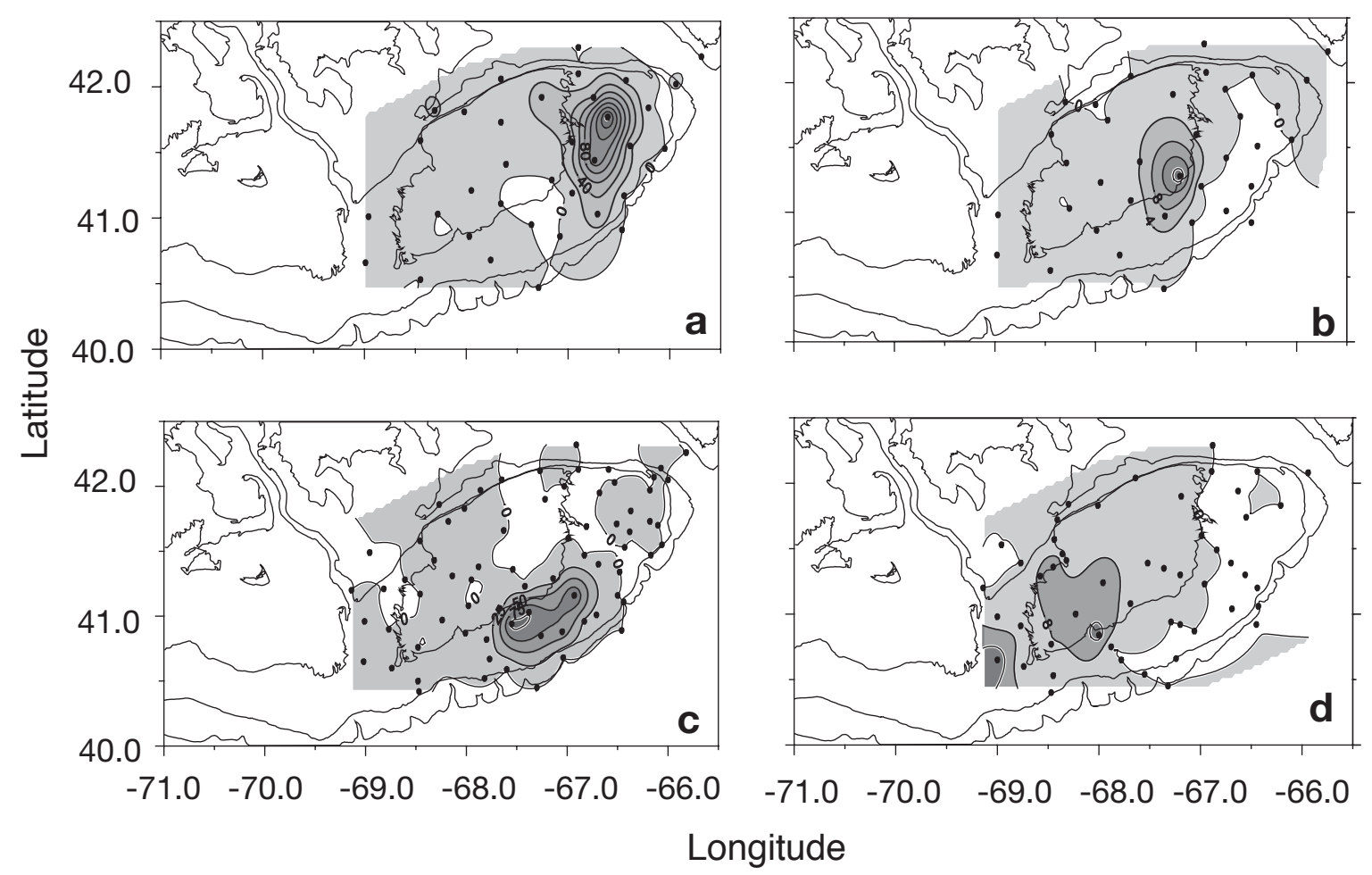

Fig. 10. Gadus morhua. Distribution of 65 d larval cohort in (a) March and (b) April 1995 and in (c) March and (d) April 1996 (no. $10 \mathrm{~m}^{-2}$ ). Station positions as in Fig. 1
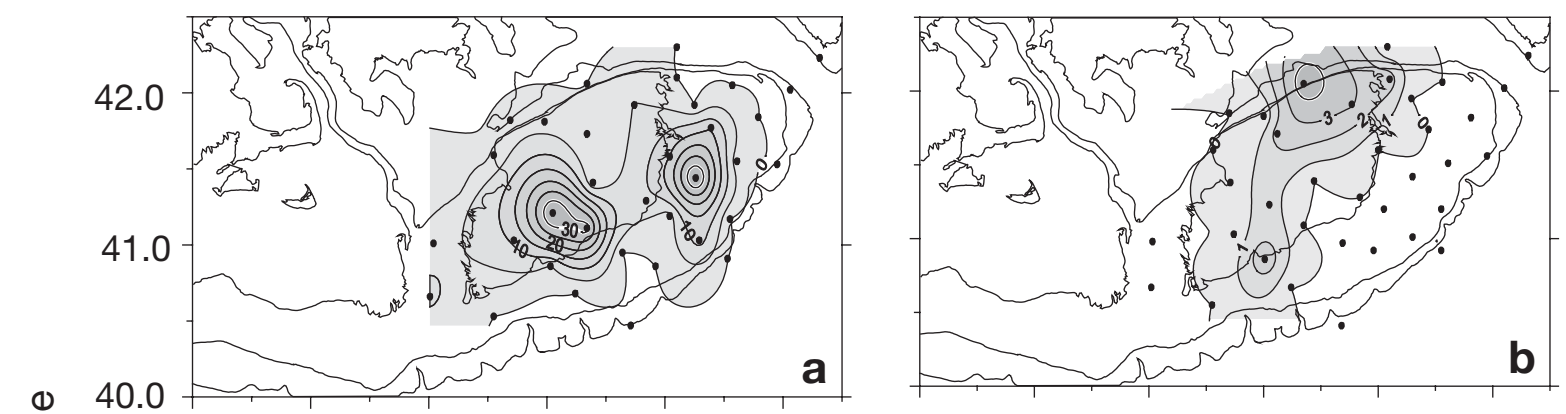

음
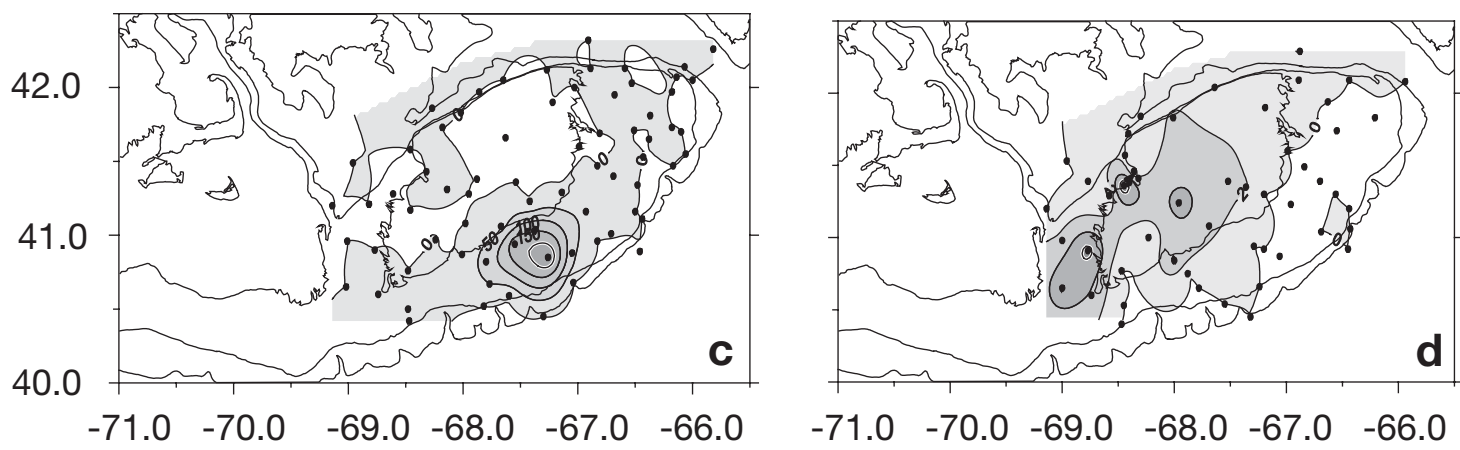

\section{Longitude}

Fig. 11. Gadus morhua. Distribution of 55 d larval cohort in (a) March and (b) April 1995 and in (c) March and (d) April 1996 (no. $10 \mathrm{~m}^{-2}$ ). Station positions as in Fig. 1 


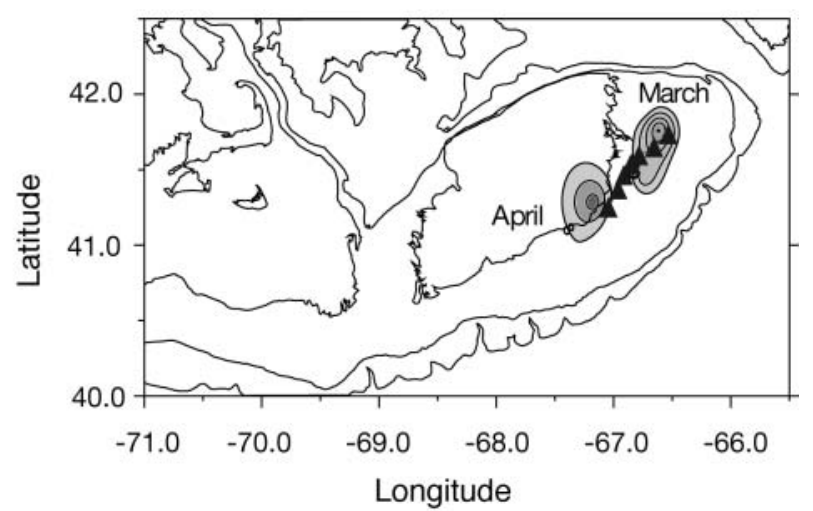

Fig. 12. Gadus morhua. Locations of highest abundances of 65 d larval cohort in March and April 1995 (Fig. 10). (A) $30 \mathrm{~d}$ mid-depth movement to southwest predicted by climatological flow field. Each triangle represents $5 \mathrm{~d}$ increment of drift

portion also may have moved west out of the sampling area. An estimate of the $55 \mathrm{~d}$ cohort abundance is included in Table 2 and is used in the larval-mortality calculations.

As with cod, the displacement of the haddock larval cohorts around the bank was consistent with the climatological mean mid-depth flow. For example, the peak of the haddock $45 \mathrm{~d}$ cohort was located on the southeastern flank of Georges Bank in February 1996 and about $100 \mathrm{~km}$ further to the southwest in March 1996 (Fig. 14). This displacement is similar to that which would have been expected from the mean flow pattern (triangles in Fig. 14). The location of the March haddock larval distribution south of the mean flow path

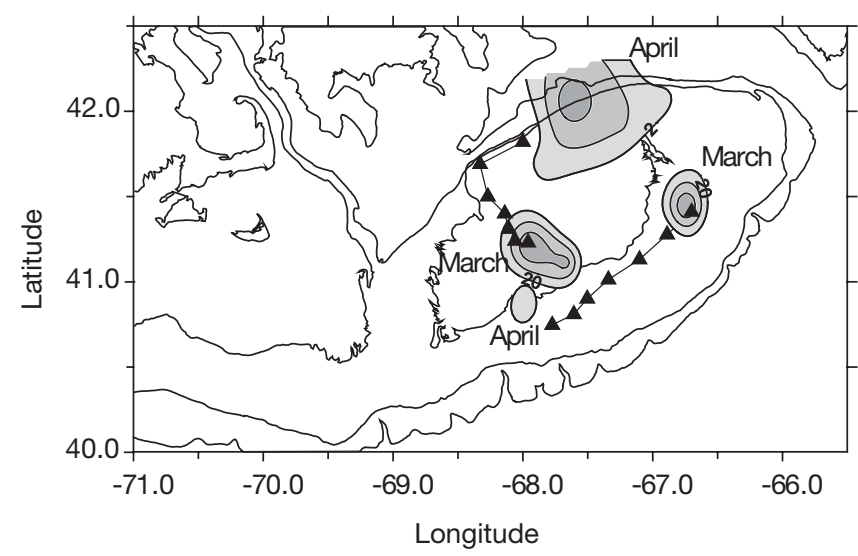

Fig. 13. Gadus morhua. Locations of 2 high abundance areas for the $55 \mathrm{~d}$ cod larval cohort observed in both March and April 1995 (see FIg. 11). Triangles represent $30 \mathrm{~d}$ mid-depth drift tracks predicted by the climatological flow field, starting at both of the March concentrations. Each triangle represents a $5 \mathrm{~d}$ increment of drift

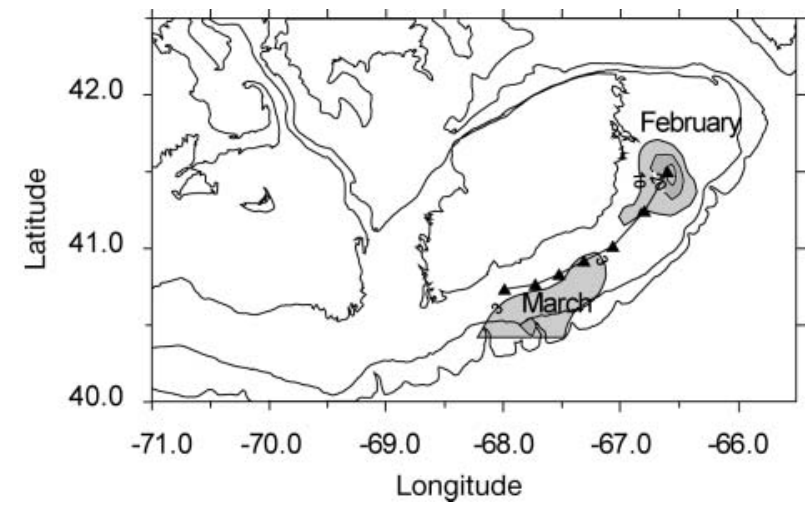

Fig. 14. Melanogrammus aeglefinus. Locations of the peak abundances for the $45 \mathrm{~d}$ haddock larval cohort in February and March 1996. Triangles represent $30 \mathrm{~d}$ mid-depth drift tracks predicted by the climatological flow field, with each triangle representing a $5 \mathrm{~d}$ increment of drift

may have been due to the early March 1996 wind event discussed above (see Fig. 3). Also similar to the cod distributions, the haddock cohorts in 1996 were further clockwise around the bank then in 1995, as illustrated by the March distributions for the $65 \mathrm{~d}$ cohorts in both years (Fig. 15).

\section{DISCUSSION}

The results reported here represent the first instance where larval mortality rates for gadid populations have been determined for discrete cohorts within the developing year classes over their first 1 or 2 mo of life. Mortality appeared chronic, with no indication that individual events disproportionately determined the overall larval mortality or that cohorts experienced especially higher or lower mortality as a result of poorer or better conditions for survival. The mortality rates for cod larvae ( 3 to $10 \% \mathrm{~d}^{-1}$ ) are somewhat lower than the 6 to $12 \%$ range reported in the literature (e.g. Gamble \& Houde 1984, Lough 1984, Sundby et al. 1989). The rates for haddock larvae (6 to $16 \%$ ) are comparable to literature values (e.g. Lough 1984, Saville 1956). The major difference between the results for the 2 species is the decrease in mortality rate with increasing larval age for haddock (Fig. 8) and no significant decrease with increasing age for cod (Fig. 7).

Houde \& Zastrow (1993), comparing literature values of larval mortality for a variety of species, noted an increase in mortality rates of about $1 \%{ }^{\circ} \mathrm{C}^{-1}$. In a similar study, Pepin (1991) found no temperature dependence in the mortality rates of yolk-sac larvae, but did so for older larvae. No seasonal pattern was evident in the mortality rates for either cod or haddock in the preset 


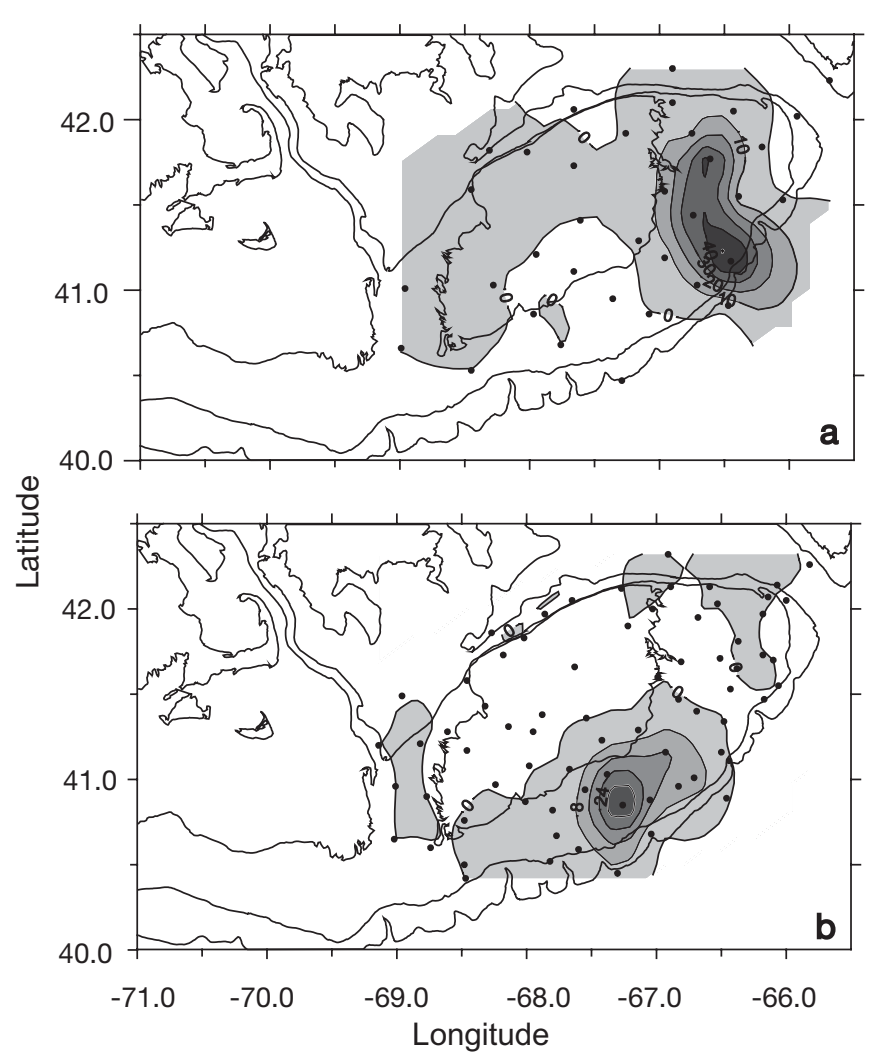

Fig. 15. Melanogrammus aeglefinus. Distribution of $65 \mathrm{~d}$ larval cohort in (a) March 1995 and (b) March 1996 (no. 10 m²). Station positions as in Fig. 1

study (Figs. $5 \& 6$, respectively). However, the watercolumn temperature on the southern flank of Georges Bank increased by only $\sim 2^{\circ} \mathrm{C}$ from the March through the May survey periods in both years. This increase is small compared to the $>20^{\circ} \mathrm{C}$ range for the data used by both Pepin (1991) and by Houde \& Zastrow (1993).

The cod cohort distributions in Figs. $10 \& 11$ indicate 2 characteristic differences between 1995 and 1996. Larvae of comparable age were further around the bank to the southwest in 1996 than in 1995, and in 1995 they were located further shoalward, or onto the shallow center part of the bank, than in 1996. These differences were also evident in the $75 \mathrm{~d}$ and $85 \mathrm{~d}$ cohorts for cod and the few comparisons that were possible for haddock (e.g. see Fig. 15). An additional difference is that the $55 \mathrm{~d}$ cod cohort in 1995 was distributed in 2 high-density concentrations that persisted from March to April, unlike the other cohorts in the present study or the characteristic pattern described by Lough (1984).

The differences in cohort location between 1995 and 1996 could be due either to differences in where the cohorts originated or in their subsequent displacement by the currents. Since the early-stage eggs in all surveys were concentrated in nearly the same area of the northeast part of the bank, differences in circulation would seem the likely cause. The moored current measurements and satellite-drifter tracks made by other components of the Georges Bank GLOBEC program do not provide a direct comparison of the advection rates from the northeast part to the southern flank of the bank in the late winter and spring of 1995 and 1996. The distribution of water properties does provide some insight into differences in circulation between the years. In February 1995, low-salinity water from the Scotian Shelf encroached onto the eastern edge of Georges Bank, causing a sharp salinity gradient (Fig. 16). Satellite-tracked drifters deployed west of the gradient area followed the expected, general clockwise flow around the bank, but did not penetrate the northeast corner of the bank where the low-salinity water was located. The encroachment of the Scotian Shelf water apparently had altered the flow pattern on the northeast part of the bank. The early-stage eggs in February were located within the Scotian Shelf water feature (Fig. 9a). As noted in 'Results', the lack of displacement from the early-stage egg distribution in February 1995 to that of the $65 \mathrm{~d}$ larval cohort in March suggests that little net transport occurred on the northeast part of the bank at that time. The differences in location between 1995 and 1996 for this cohort originated from the lack of transport from February to March 1995 associated with the Scotian Shelf Water feature. This alteration of the normal circulation also would have similarly affected the locations of the $75 \mathrm{~d}$ and $85 \mathrm{~d}$ cohorts in 1995 that were in the water column as eggs during late February and early March.

The late-stage eggs in February 1995 were mainly west of the Scotian Shelf water feature (Fig. 9b). The climatological flow field would account for the transport of these eggs to the western concentration of the $55 \mathrm{~d}$ larval cohort in March, provided that a small onbank component were added to the drift. A satellite

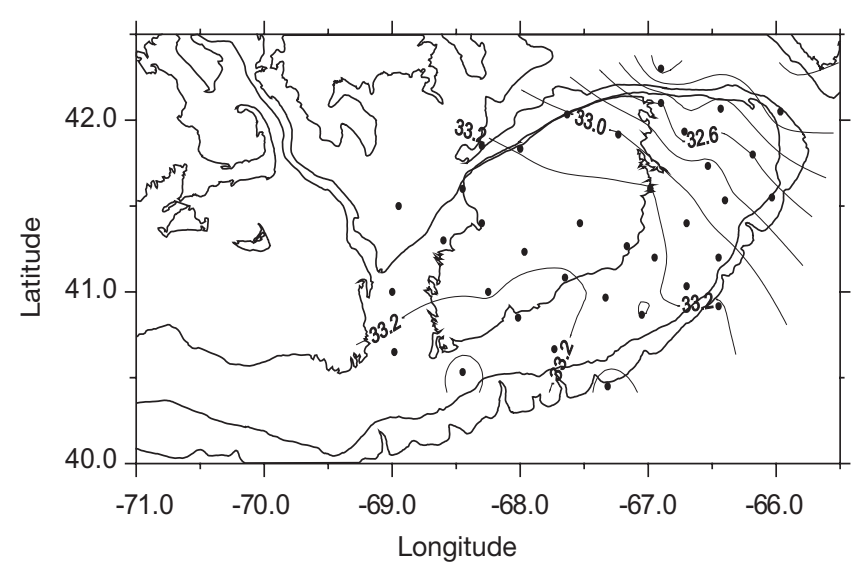

Fig. 16. Surface salinity distribution in February 1995. Station positions as in Fig. 1 
drifter deployed on the station just northwest of the center of the late-stage egg patch in February did exhibit cross-isobath movement into the shoal region of the bank, indicating that on-bank movement was occurring that was not characteristic of the climatological flow field. This on-bank tendency may have been associated with the presence of a Gulf Stream ring along the southeastern edge of the bank (Naimie et al. 2001), although there is no indication of encroachment of the ring onto the southern flank of the bank. Whatever the cause, the cross-isobath, shoalward movement also would have affected the movement of the other cohorts that were in the water column at the time. The shoalward location of the $55 \mathrm{~d}$ larval cod patch in March resulted in its subsequent drift to the northern side of the bank by April (Fig. 11b). The same cohort in 1996, located on the southern flank of the bank in March, was carried westward to near Great South Channel. This large difference in the April locations resulted from a subtle cross-isobath component to the flow in 1995 on the eastern part of the bank, beginning in February when the cohorts were first hatched.

The eastern concentration of the $55 \mathrm{~d}$ cod cohort in March 1995 (Fig. 11a) probably originated from appropriate aged eggs in February located within the salinity gradient region - between the centers of the earlyand late-stage egg distributions (Fig. 9a-b). From February to March, these eggs and subsequent developing larvae would have experienced an intermediate degree of displacement between the lack of transport experienced by the early-stage eggs and the westward movement of the late-stage eggs located west of the salinity-gradient region.

In April 1996, much of the $65 \mathrm{~d}$ cod cohort appears to have drifted out of the sampling area toward the west. At the same time, the $10 \mathrm{~d}$ older $55 \mathrm{~d}$ cohort had moved northward into the Great South Channel. Given the characteristic clockwise circulation, the location in the channel would promote retention of the cohort on the bank. Modeling studies (Werner et al. 1993) have

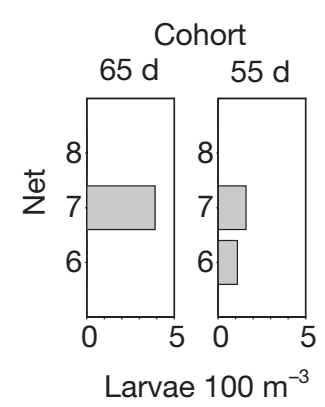

Fig. 17. Gadus morhua. Vertical distribution of cod larvae (no. $100 \mathrm{~m}^{-3}$ ) for the 65 and $55 \mathrm{~d}$ cohorts at standard Stn 2 (see Fig. 1) in April 1996. The depth increments are 0 to $15 \mathrm{~m}$ for Net 8,15 to $45 \mathrm{~m}$ for Net 7 and 45 to $60 \mathrm{~m}$ for Net 6 shown that retention through Great South Channel probably occurs for larvae that are deeper in the water column as they are carried toward the southwest corner of Georges Bank. The vertical distribution of the 55 and $65 \mathrm{~d}$ cod cohorts at the southwesternmost station in March 1996 (Stn 2, Fig. 1) shows that the 55 d cohort was distributed throughout the deeper parts of the water column, while the $65 \mathrm{~d}$ cohort was concentrated at mid-depth (Fig. 17). The movement of the $55 \mathrm{~d}$ cohort into Great South Channel while the $65 \mathrm{~d}$ cohort moved west toward the Middle Atlantic Bight in April 1996 is believed to be due to the interaction of the circulation pattern and larval behavior, as suggested by Werner et al. (1993). It should be noted that movement of the $65 \mathrm{~d}$ cohort westward toward the Middle Atlantic Bight does not imply death or a permanent loss of those fish from the Georges Bank population. Polacheck et al. (1992) documented the transport of the 1987 Georges Bank haddock larval population into the Middle Atlantic Bight and its apparent return to the bank as $1 \mathrm{yr}$ old fish the following spring.

Despite the apparent differences in circulation and the resulting differences in location of the various cohorts, the estimated mortality rates were indistinguishable between the 2 years for each species (Figs. 5 \& 6). An estimate of mortality over the entire first year of life is derived by comparing the total number of eggs hatched to the number of recruits or $1 \mathrm{yr}$ old fish that resulted. The total egg hatching is the sum of the daily values forming the curves in Fig. 2. For consistency between years, the summation was done for midFebruary through June, which omits earlier hatching that was not sampled in both years. The total hatching, therefore, is somewhat underestimated, particularly for cod. The $1 \mathrm{yr}$ old fish abundance is estimated by a virtual population analysis of the adult cod (O'Brien \& Cadrin 1999) and haddock (Brown \& Munroe 2000). The total egg hatching and the estimated number of $1 \mathrm{yr}$ old fish are listed in Table 3 for each species for both years. The ratio of the $1 \mathrm{yr}$ old abundance to the number of hatched eggs provides a survival index (Table 3) reflecting the integrated mortality over the first year of life. The survivorship indices for haddock are about 3 times those for cod, which is surprising given the higher larval mortality rate estimates for haddock. The haddock mortality rates were estimated only for young larvae, and their decline with age suggests that lower rates would apply to older larvae. The survivorship indices are very similar between years for each species, suggesting that the integrated mortality for each was similar in 1995 and 1996. The indices indicate that the similarity in recruitment for cod and difference in recruitment for haddock in the 2 yr was evident at the egg-hatching stage for those year-classes. This suggests that the year class strength for both spe- 
cies in the 2 yr was not determined by variations in mortality during the larval and juvenile stages. In contrast, none of the egg or larval abundance indices considered by Campana et al. (1989) could rank-order the subsequent recruitment levels for 3 year-classes of either cod or haddock in their dataset. Similarly, Sundby et al. (1989) found a good relationship between year-class strength and an early juvenile index, but not with abundance at earlier life stages.

Determining rigorous confidence limits for the abundance (Table 1) and mortality estimates (Figs. 5 \& 6) would be difficult, and none are given. The larval abundance at a station is determined from catches by 2 types of net systems - bongo and MOCNESS. For some stations abundance was estimated from 1 sample (a bongo tow), while for other stations abundance was estimated from 2 samples (a bongo and a MOCNESS). Although 35 to 80 stations contributed to the estimated abundance for a survey, many stations had zero catches, and the bulk of the abundance was derived from only a few stations. The spatial integration of the station values to a bank-wide abundance estimate could contribute additional uncertainty, since the spatial statistics of the true larval distribution are unknown. Also, many of the mortality estimates were determined from the decrease between an egg-hatching estimate and a subsequent larval-abundance estimate, with the former having additional sources of uncertainty associated with it.

The mortality-rate calculation is not sensitive to the estimated absolute abundance on a survey, but to the relative change in abundance between surveys. As an alternative to the kriging method, the calculations were repeated by linearly interpolating the observed larval density values (log-transformed) to the Bank150 grid points, with a $1 / \mathrm{R}^{2}$ weighting of the same 6 nearest observed values used with kriging (where $\mathrm{R}$ is the distance from the observed value to the grid point). The abundance estimates using kriging were consistently lower than those using the linear interpolation, but the resulting mortality estimates were nearly always within $\pm 1 \% \mathrm{~d}^{-1}$. Therefore, the method used to determine the bank-wide population abundance (e.g. kriging in this case) is not considered a contributing source of error in the mortality estimation.

The consistency of the cod mortality estimates (Fig. 7) provides insight into the uncertainty in the abundance estimates. The mortality estimates are largely distributed between 3 and $7 \% \mathrm{~d}^{-1}$, or $5 \pm 2 \%$ $\mathrm{d}^{-1}$. These values were determined by the exponential decrease in abundance over an approximately $30 \mathrm{~d}$ period. $\mathrm{A} \pm 30 \%$ variation in abundance estimates used in the mortality calculation would result in approximately a $\pm 2 \% \mathrm{~d}^{-1}$ variation in the mortality estimate. Assuming no other source for the variation in mortality
Table 3. Gadus morhua and Melanogrammus aeglefinus. Number of hatched eggs, number of 1 yr old recruits to stock from those eggs, and ratio of recruits to hatched eggs, for cod and haddock in 1995 and 1996

\begin{tabular}{|lcccc|}
\hline Species & Year & $\begin{array}{c}\text { Recruits } \\
\left(\times 10^{-3}\right)\end{array}$ & $\begin{array}{c}\text { Eggs } \\
\left(\times 10^{-12}\right)\end{array}$ & $\begin{array}{c}\text { Ratio } \\
\left(\times 10^{6}\right)\end{array}$ \\
\hline Cod & 1995 & 6246 & 3.02 & 2.1 \\
& 1996 & 6456 & 3.73 & 1.7 \\
Haddock & 1995 & 9908 & 1.65 & 6.0 \\
& 1996 & 19530 & 3.66 & 5.3 \\
\hline
\end{tabular}

rates, the consistency in Fig. 7 would imply that the relative abundance estimates are good to within about $\pm 30 \%$. It is expected that spatial and temporal variation in food, physics and predators contributed to variability in the larval mortality rates, and therefore that the abundance estimates are probably better than the $\pm 30 \%$ value. However, attributing modest changes in mortality rate (e.g. $\pm 2 \% \mathrm{~d}^{-1}$ ) to physical or biological forcing will be problematic, and will probably rely more on the consistency of patterns between variables than on the rigor of individual parameter estimates. The haddock abundance estimates were based on fewer fish than the cod values, and are likely to be subject to a greater degree of uncertainty.

\section{CONCLUSIONS}

Our primary conclusions are: (1) Egg mortality rates in 1995 and 1996 for both cod and haddock were considerably higher than comparable rates calculated from the MARMAP data set (1978 to 1987). (2) Larval mortality rates in 1995 and 1996 were fairly uniform throughout the season, across cohorts and between years. (3) Haddock larvae appeared to suffer higher mortality at younger ages, while for cod the rates were not highly age-dependent. Overall, the mortality rates for haddock larvae were generally higher than those for cod. (4) An intrusion of water from the Scotian Shelf onto the northeast part of Georges Bank in February 1995 appeared to alter the circulation in that region. The change in circulation resulted in differences in the location of same-aged larval cohorts between 1995 and 1996. (5) Away from the Scotian Shelf water intrusion, the movement of larval cohorts between monthly surveys was consistent with the mid-depth climatological flow field around Georges Bank. (6) A reduction in the egg-hatching rate during March 1996 appears to have been related to a wind event that probably transported eggs off the southern side of Georges Bank. (7) Survivorship from egg hatching to recruitment for haddock was about 3 times higher than that for cod. 
Acknowledgements. The samples used in this analysis were collected by a large number of GLOBEC investigators and technicians who worked together on the GLOBEC BroadScale survey cruises, and we thank them all. We also thank the captains and crews of the RVs 'Albatross IV', 'Oceanus' and 'Endeavour' for their skill and assistance during these cruises. Dick Limeburner of the Woods Hole Oceanographic Institution kindly made available his drifter data used in Fig. 3. Three anonymous reviewers provided valuable comments that greatly improved the final version of this manuscript. This is US GLOBEC contribution no. 399.

\section{LITERATURE CITED}

Berrien P, Sibunka J (1999) Distribution pattens of fish eggs in the northeast continental shelf ecosystem. NOAA Tech Rep NMFS 145:1-310

Brown RW, Munroe NJ (2000) Stock assessment of George Bank haddock, 1931-1999. Northeastern Fisheries Science Center Ref Doc 00-12. National Marine Fisheries Service, Woods Hole, MA

Campana SE, Frank KT, Hurley FCF, Koeller PA, Page FH, Smith PC (1989) Survival and abundance of young Atlantic cod (Gadus morhua) and haddock (Melanogrammus aeglefinus) as indicators of year-class strength. Can J Fish Aquat Sci 46(Suppl 1):171-182

Deutsch CV, Journel AG (1998) GSLIB, geostatistical software library and user's guide. Oxford University Press, New York

Gamble JC, Houde ED (1984) Growth, mortality and feeding of cod (Gadus morhua L.) larvae in enclosed water columns and in laboratory tanks. Flødevigen Rapp 1:123-143

GLOBEC (Global Ocean Ecosystem Dynamics) (1992) Northwest Atlantic implementation plan, Report No. 6

Green J, Jones R, Brownell S (2003) Age and growth of larval cod and haddock from the 1995 and 1996 on Georges Bank. Mar Ecol Prog Ser (in press)

Harding D, Ramster J, Nichols JH, Folkard AR (1978) Studies on planktonic fish eggs and larvae in relation to environmental conditions in the west central North Sea. Ann Biol (Cph) 33:62-75

Hardy JD Jr (1978) Development of fishes of the Mid-Atlantic Bight: an atlas of egg, larval and juvenile stages, Vol II. Anguillidae through Syngnathidae. Biological Services Program, US Fish and Wildlife Service FWS/OBS-789/ 12.455. US Government Printing Office, Washington, DC

Heesen HJL, Rijnsdorp AD (1989) Investigation on egg production and mortality of cod (Gadus morhua L.) and plaice (Pleuronectes platessa L.) in the southern and eastern North Sea in 1987 and 1988. Rapp PV Réun Cons Int Explor Mer 191:15-20

Houde ED, Zastrow CE (1993) Ecosystem- and taxon-specific dynamic and energetics properties of larval fish assemblages. Bull Mar Sci 53:290-335

Lough RG (1984) Larval fish trophodynamic studies on Georges Bank: sampling strategy and initial results. Flødevigen Rapp 1:395-434

Editorial responsibility: Kenneth Sherman (Contributing Editor), Narragansett, Rhode Island, USA
Lough RG, Bolz GR, Pennington M, Grosslein MD (1985) Larval abundance and mortality of Atlantic herring (Clupea harengus L.) spawned in the Georges Bank and Nantucket Shoals areas, 1971-1987 seasons, in relation to spawning stock size. J Northwest Atl Fish Sci 6:21-35

Morse WW (1989) Catchability, growth, and mortality for larval fishes. Fish Bull US Natl Mar Fish Serv 87:417-446

Naimie CE, Loder JW, Lynch DR (1994) Seasonal variation of the three-dimensional residual circulation on Georges Bank. J Geophys Res 99:15967-15989

Namie CE, Limeburner R, Hanna CG, Beardsley R (2001) On the geographic and seasonal patterns of the near-surface circulation on Georges Bank-from real and simulated drifters. Deep-Sea Res Part II Top Stud Oceanogr 48: 501-518

O'Brien L, Cadrin SX (1999) Assessment of the Georges Bank Atlantic cod stock for 1998. Northeastern Fisheries Science Center Ref Doc 99-03. National Marine Fisheries Service, Woods Hole, MA

Page FH, Frank KT (1989) Spawning time and egg stage duration in Northwest Atlantic haddock (Melanogrammus aeglefinus) stocks with emphasis on Georges and Browns Bank. Can J Fish Aquat Sci 46:68-81

Pennington M, Berrien P (1984) Measuring the precision of estimates of total egg production based on plankton surveys. J Plankton Res 6:869-879

Pepin P (1991) Effect of temperature and size on development, mortality and survival rate of pelagic early life history stages of marine fish. Can J Fish Aquat Sci 48:503-518

Polacheck T, Mountain D, McMillan D, Smith W, Berrien P (1992) Recruitment of the 1987 year class of Georges Bank haddock (Melanogrammus aeglefinus): the influence of unusual larval transport. Can J Fish Aquat Sci 49: 484-496

Saville A (1956) Eggs and larvae of haddock (Melanogrammus aeglefinus L.) at Faroe. Mar Res 4:1-27

Serchuk FM, Grosslein MD, Lough RG, Mountain DG, O'Brien L (1994) Fishery and environmental factors affecting trends and fluctuations in the Georges Bank and Gulf of Maine Atlantic cod stocks: an overview. ICES Mar Sci Symp 198:77-109

Sundby S, Herman B, Soldal AV, Olsen S (1989) Mortality rates during the ealy life stages and year-class strength of northeast Arctic cod (Gadus morhua L.). Rapp PV Réun Cons Int Explor Mer 191:351-358

Thompson BM, Riley JD (1981) Egg and larval development studies in the North Sea (Gadus morhua L.). Rapp PV Réun Cons Int Explor Mer 178:553-559

Werner FE, Page FH, Lynch DR, Loder JW, Lough RG, Perry RI, Greenberg DA, Sinclair MM (1993) Influences of mean advection and simple behavior on the distribution of cod and haddock early life stages on Georges Bank. Fish Oceanogr 2:43-64

Wiebe PH, Morton AW, Bradley AM, Backus RH, Craddock JE, Barber V, Cowles TJ, Flierl RG (1985) New developments in the MOCNESS, an apparatus for sampling zooplankton and microneckton. Mar Biol 87:313-323

Submitted: October 25, 2002; Accepted: July 2, 2003

Proofs received from author(s): November 3, 2003 